\title{
El sentido de lo imaginario en Castoriadis y el psicoanálisis ${ }^{2}$
}

\author{
The Sense of Imaginary in Castoriadis and Psychoanalysis
}

\begin{abstract}
Resumen
El artículo examina el sentido del término imaginario de Cornelius Castoriadis en su escrito Lo imaginario: la creación en el dominio histórico-social y en otros dos ensayos de sus lectores Ángel Carretero y Nicolás Poirier, quienes muestran proximidades y distancias entre las concepciones de Castoriadis y la teoría psicoanalítica. La autora de este texto sopesa el valor explicativo de los comentarios y, como practicante clínica del psicoanálisis, señala algunas imprecisiones en las que incurre el primero de los lectores mencionados.
\end{abstract}

Palabras clave: Imaginario, dogmas filosóficos, psicoanálisis, comentaristas, tergiversación.

\begin{abstract}
This article studies the sense of the word imaginary in the text "The Imaginary: Creation in the SocialHistorical Domain" written by Cornelius Castoriadis and furthermore the analysis made by two readers: Angel Carretero y Nicolás Poirier who demonstrate proximities and distances between the perspective of Castoriadis and psychoanalytic theory. The author of this paper compares the explanatory value of the comments and, as a clinical practitioner of psychoanalysis, calls the attention about vagueness in the perspectives of Carretero.
\end{abstract}

Palabras clave: Imaginary, Philosophical dogma, Psychoanalysis, commentators, Distortion.

Recibido el 26 de abril de 2013 y aprobado el 19 de junio de 2013

1 Médica Cirujana, con estudios en el Laboratorio de Genética Humana de la Universidad Nacional de Colombia, bajo la dirección de Emilio Yunis. Estudios de Psicoanálisis en la Universidad París VIII en Saint Denis y en la Séction Clinique de l'École de la Cause Freudienne. Especialista en Ética de Uniminuto. Candidata a Magister en Estudios Sociales de la Universidad Pedagógica Nacional. Distinciones en el campo de las letras: una de ellas el Accésit Lucien Freud 2008 en Psicoanálisis y Cultura, otorgado por la Fundación Proyecto al Sur de Buenos Aires. Correo electrónico: egofatuo@gmail.com

2 El presente artículo surge como reflexión durante el proyecto de investigación Ética del sujeto e ideología en el deporte contemporáneo. Estudio de casos bajo la perspectiva psicoanalítica, realizado en el marco de la Maestría en Estudios Sociales de la Universidad Pedagógica Nacional. Bogotá, Colombia. 


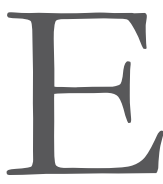

$\mathrm{n}$ su artículo Lo imaginario: la creación en el dominio histórico-social el pensador franco-griego Cornelius Castoriadis se propone responder dos preguntas: La primera es ¿qué da unidad a una sociedad?; la segunda, definir ¿cómo emergen nuevas formas histórico-sociales?

A la primera pregunta responde que las instituciones son las encargadas de producir una interpretación, el magma o conjunto de significaciones imaginarias con las cuales una sociedad catectiza el mundo y su propia vida en él, puesto que allí, en la dimensión imaginaria: "la existencia es significación" (Castoriadis, 1988, p. 71). De este modo subraya el sentido fundante de la institución como creación originaria del sentido histórico-social del colectivo, que supera toda producción de los individuos o de la subjetividad, dando un paso más allá de la concepción fenomenológica de la sociedad como intersubjetividad.

A la segunda pregunta responde que las nuevas formas histórico-sociales surgen por una creación, que en tanto fruto de la experiencia colectiva, no puede ser explicada, sino dilucidada (Castoriadis, 1988, p. 77), pues carece de causa.

La argumentación del texto desemboca en la explicación sobre cómo aparece una nueva forma de ser histórico-social —primero en la Antigua Grecia y al finalizar la Edad Media en Europa- a partir de esa apertura en Occidente que surge como autonomía (Castoriadis, 1988, p. 77). El autor afirma allí que la creación de la Filosofía y de la Democracia es el índice de que esas sociedades occidentales habrían logrado cuestionar su propia institución, su cosmovisión y sus significaciones imaginarias, lo cual abrió la posibilidad, no sólo a las discusiones que actualmente libramos, sino al surgimiento de "una verdadera acción política", a una acción social dirigida a "establecer una nueva institución de la sociedad, con miras a realizar plenamente el proyecto de autonomía” (Idem.).

Sin embargo, a la luz de la historia reciente, ¿cómo entender esta conclusión de semejante optimismo para Occidente? Su referencia a la autonomía suscita un primer interrogante sobre el sentido que puede tener el término en el conjunto de la obra del autor (que hasta ahora no conocemos). Un segundo interrogante es la objeción que representa el inconsciente freudiano a la idea moderna de autonomía y la omisión de esta instancia que hace Castoriadis, tomando en cuenta que es psicoanalista. Finalmente, hay un tercer interrogante sobre la relación entre la autonomía y el sentido específico de lo imaginario en su elaboración.

\section{Castoriadis y el psicoanálisis}

En ciertos momentos nos parece que el sentido de los términos que construye Castoriadis exigiría olvidar su condición de psicoanalista e introducirse en el ámbito filosófico, puesto que de entrada - como él mismo indica- pide al lector admitir cinco dogmas. Procedimiento ajeno tanto a Marx como a Freud: las fuentes donde abrevó para adoptar los caminos del socialismo y del psicoanálisis. De un lado, porque tal procedimiento no concuerda con los propósitos de Marx de transformar la realidad (más allá de interpretarla) a partir del análisis concreto de la situación concreta. Tampoco se aviene con la elección clínica de Freud, quien toma "a la letra" la palabra de los analizantes, dando al significante el estatuto de causa material de las formalizaciones psicoanalíticas.

Sin embargo, las afirmaciones de Castoriadis revelan algo del origen de esos dogmas. El primero de ellos concierne a un ser caótico y abismal, que no obstante estaría organizado y nos remite al Es (ello) freudiano o a lo real lacaniano. El segundo dogma afirma "El ser es tiempo" (1988, p.64), acto seguido liga este dogma al tercero, haciendo equivaler estos dos términos a la creación, con la frase: "El tiempo no es nada o es creación" (Idem.). Parece entonces que también en ese "tiempo-creación" de Castoriadis hay elementos del psicoanálisis. Me explico: Si Freud buscó algo fue precisamente revelar el tiempo lógico del sujeto en el sentido 
de los síntomas, que son una escritura de la experiencia subjetiva, cuyas marcas de memoria llegan a actualizarse una y otra vez en un tiempo independiente de la cronología. Hegel había situado que: "el concepto es el tiempo de la cosa" (Kojeve, 1982, p. 31); en cambio Freud escucha en su praxis los testimonios de la repetición de eventos históricos cifrados en el síntoma, así, lo inconsciente parece estar "fuera del tiempo" para el sujeto, en razón de que es el tiempo puro de la cosa, como afirma Lacan:

[...] porque él [el inconsciente] es el tiempo de sí mismo, el tiempo puro de la cosa, y en tanto tal, puede reproducirla según cierta modulación, cuyo soporte material puede ser cualquier cosa. En el automatismo de repetición se trata precisamente de esto (1975, p. 238).

Encontramos en Castoriadis la idea del tiempo-ser, pero el citado automatismo no, si bien debió conocerlo, como psicoanalista y esposo de la también psicoanalista Piera Aulagné. Sin embargo, al parecer el autor se orientó más hacia los fenómenos sociales que al clínico, práctica de la cual extrae su teoría el psicoanálisis. Por eso y ante la necesidad de situar el sentido específico de los términos que impone la teorización sociológica de Castoriadis, parecería forzoso recurrir a los comentaristas que conocen más ampliamente su obra.

Por fortuna, Nicolás Poirier no sólo hace una labor que permite desentrañar tanto las diferencias entre el sentido de lo imaginario, la imaginación y las significaciones imaginarias, como del término autonomía en las construcciones de Castoriadis, además de eso, señala puntos de articulación entre éstas y la elaboración freudiana.

Hay que estar atento al sentido que Castoriadis da a la idea de autonomía. No hay que entenderla al modo de Descartes, que hace de la consciencia una sustancia cerrada cuya esencia se reduce al hecho de pensar (se), ni al modo de Kant, en cuya obra el sujeto moral obedece leyes que se ha dado de una vez y para siempre (Poirier, 2006, p. 58).

En efecto, como en Freud, el sujeto del que se trata en Castoriadis es inherente al objeto y si bien no existe ningún interés ni imperativo que el psicoanálisis encargue al sujeto respecto al mundo, al elegir éste las vías de su satisfacción influirá de modo distinto en su entorno.

[...] la autonomía en el sentido de Castoriadis no es el simple modo de una intencionalidad primera mediante la cual el sujeto contempla a los otros; no es solamente forma sino un contenido bien definido: la instauración de una nueva relación entre el deseo del individuo y su conciencia. Así, la autonomía debe entenderse en el sentido freudiano como facultad de engendrar un pensamiento reflexivo en lugar de las pulsiones inconscientes de las cuales el sujeto es mero juguete (Poirier, 2006, p. 59).

Vemos el influjo del imperativo ético de Freud, que invita a resistirse a los cantos de sirena de "lo in-sabido" (Unbewusste ${ }^{3}$, transmitido al sujeto por las instituciones (el Otro de

3 Unbewusste es el término alemán usado por Freud y vertido al español como inconsciente, traducción que omite la referencia al saber bewusste y a su privación Un, cuya traducción literal sería in-sabido.

4 Esta expresión Wo Es war Ich werden de Freud, aparece por primera vez en "El yo y el ello" de 1923 y reaparece en la conferencia $31^{\text {a }}$ que es una reelaboración de ese texto y parte de las "Nuevas conferencias de introducción al psicoanálisis" de 1932. Lila Isacovich, de la Fundación Buenos Aires, Asistencia y formación en psicoanálisis, ha escrito un artículo donde analiza esta frase y hace la lista de las traducciones que se han hecho de la misma:

1) Where id was, there ego shall be (Strachey), vertida al castellano como :"Donde eso era, allí el ego será",

2) Donde era ello, ha de ser yo (López Ballesteros), 3) Donde Ello era, Yo debo devenir (Etcheverry).

(Isacovich).

Ahora bien, es Lacan quien hace la inclusión del sujeto en esa traducción, más exactamente durante el Seminario 6, dictado entre 1958 y 1959, El deseo y su interpretación, cuando explica: 
Lacan) y que aparece citado por Poirier al pie de página Wo Es war Ich werden ${ }^{4}$ : Allí donde eso era, yo (como sujeto) debo advenir. Nicolás Poirier muestra en su comentario que con la idea de autonomía Castoriadis alude a ese imperativo ético, la opción de elegir que Freud formulara para el sujeto respecto a lo inconsciente:

En otras palabras el accionar autónomo consiste, según Castoriadis, en la aptitud de impedir que el inconsciente determine nuestros actos e instaurar, en cambio, una relación reflexiva con nuestro imaginario, de suerte que ya no estemos enajenados de él. Así, la autonomía debe "entenderse como algo que no remite a un estado acabado sino a una situación activa, que no remite a una persona ideal devenida Yo de una vez para siempre, la cual pronunciaría un discurso exclusivamente suyo y no generaría fantasías, sino a una persona real que no deja de adueñarse de lo ya adquirido, del discurso del Otro, que es capaz de develar sus fantasías como tales y no se deja dominar por ellas a menos que así lo desee (Poirier, 2006, p. 60).
En esta cita, para referirse a "lo ya adquirido", Castoriadis usa la expresión que Lacan inventó para lo inconsciente: el "discurso del Otro". A pesar de que el término inconsciente no aparezca en su texto, Castoriadis se refiere a él en el sentido no-psicológico ni individual que le dio la elaboración de $\operatorname{Lacan}^{5}$.

Sobre los antecedentes del principio de nocausalidad, al que Castoriadis ubica como imaginario social instituyente, ya en 1964 Lacan pronuncia su idea de que no hay causa sino de lo que cojea (Lacan, 1973, p. 25), ubicando en la "cojera" a las formaciones del inconsciente, caracterizadas por la caída del sentido que denuncian la presencia del sujeto lacaniano ${ }^{6}$. Aquí hay coincidencia en la concepción de estructuras abiertas cuya dinámica es imprevisible, pero también una diferencia en las elaboraciones, que resaltan alguna distancia con la praxis clínica y un volcamiento sobre lo histórico-social en Castoriadis; Poirier dice sobre su idea de la historia como auto-creación, invención de un nuevo objeto:

"Me parece que no tengo más que decir aquí. Sin embargo, voy a decir más, para recordarles lo que esto significa en el discurso freudiano, por ejemplo, el "wo Es war, soll Ich werden": ahí donde eso era, yo (je) debo advenir. Esto es muy preciso; es ese "ich" que no es "das ich", que no es el yo (moi). Es un "ich" utilizado como sujeto de la frase. Ahí donde eso estaba, ahí donde eso (ça) habla. Donde eso (ça) habla, es decir, donde, en el instante anterior, algo estaba, que es el deseo inconsciente, ahí yo debo designarme, ahí yo (je) debo ser ese yo (je) que es la meta, el fin, el término del análisis ante el cual él se nombra, se forma, se articula, en tanto no lo haga jabas, pues también, en formula freudiana, ese "soll Ich werden", ese "debe ser", ese "debo advenir", es el sujeto de un devenir, de un deber que le es propuesto. Debemos reconquistar ese campo perdido del ser del sujeto, como dice Freud en la misma frase, en una divertida comparación, como la reconquista de Holanda sobre el Zuyderzeé de tierras ofrecidas a una conquista pacífica. Ese campo del inconsciente sobre el cual debemos ganar en la realización de la gran obra analítica, es seguro que se trata de eso. Pero antes de que esto sea hecho, ahí donde eso estaba, ¿qué es lo que nos designa el lugar de ese yo (je) que debe aparecer? ¿De qué es Índice eso que nos lo designa? Exactamente, de eso de lo que se trata, del deseo. Del deseo en tanto es función y término de eso de lo cual se trata en el inconsciente. Y el deseo es aquí sostenido por la oposición, la coexistencia de los dos términos que son el $\mathrm{S}$, el sujeto en tanto que, en este límite él se pierde, es que comienza el inconsciente -eso quiere decir que no hay pura y simple privación de algo que se llamaría conciencia. Otra dimensión comienza donde no les es más posible saber dónde él ya no es más conciencia. Aquí se detiene toda posibilidad de nombrarse. Pero en este punto de detención, está también el índice, el índice que es aportado, que es la función mayor, sean cuales fueren las apariencias de lo que en ese momento es sostenido ante él como el objeto que le fascina, pero también que lo retiene ante la anulación pura y simple, la síncopa de su existencia" (Lacan, p. 366).

5 En 1964, Lacan precisa el sentido del inconsciente freudiano distinguiéndolo de las múltiples acepciones que tuvo antes y después el término. En la misma sesión del 22 de enero en su seminario anuncia que él mismo le dará un nuevo estatuto al inconsciente en psicoanálisis, apoyado en el concepto de significante, aportado por la lingüística moderna, del que Freud precisó las leyes de condensación y desplazamiento en sus textos llamados lingüísticos (Cf. Lacan, 1973, p. 22). El inconsciente está pues en la superficie, el sujeto no es consciente de él, en tanto es el discurso del Otro: la simbólica que lo constituyó.

$6[$...] chaque fois que nous parlons de cause, il y a toujours quelque chose d'anticonceptuel, d'indéfini [...] Bref, il n'y a de cause que de ce qui cloche [...] Eh bien! L'inconscient freudien, c'est à ce point que j'essaie de vous faire viser par approximation qu'il se situe, à ce point où, entre la cause et ce qu'elle affecte, il y a toujours la clocherie (Lacan, 1973, p. 25). 
[...] no significa que la historia se haga o se cree a partir de nada (cum nibilo), lo que implicaría atribuir al pasado un modo de ser casi nulo, sino que es una creación inmotivada (ex nibilo), postulación primera de significaciones a partir de las cuales las sociedades pueden crear su mundo y organizarlo en cuanto realidad histórico-social singular (Poirier, 2006, p. 62).

\section{El sentido de lo imaginario en Castoriadis según sus comentaristas}

Por consiguiente, ese imaginario no es una imagen de algo, no es el imaginario como reflejo de un eidos ya dado, sino "una creación incesante y esencialmente indeterminada (social, histórica y psíquica) de figuras/formas/imágenes, sólo a partir de las cuales puede ser cuestión de algo" (Castoriadis citado por Poirier, 2006, p. 62).

Poirier hace una cita sobre ese "eidos ya dado", para decir que Castoriadis achaca esta concepción a Marx, "al psicoanálisis y en particular a Lacan: el imaginario en cuanto ideología es una concepción invertida de la realidad" (2006, p. 62). Independientemente de si esta idea es de Poirier o de Castoriadis, lo que habría que aclarar aquí es que para el psicoanálisis y desde un punto de vista clínico, la realidad es un constructo entre imaginario y simbólico, que depende de cada sujeto, por tanto no hay "realidad común", lo que interesa de ella al analista es lo que hace verdad para el sujeto que sufre. De hecho, en su texto de 1924 La pérdida de la realidad en la neurosis y la psicosis Freud muestra su carácter deleznable.

Esta cita que distancia a Castoriadis de Marx y del psicoanálisis nos devuelve a la pregunta en torno a su optimismo sobre la posibilidad de "realizar plenamente el proyecto de autonomía” en las sociedades occidentales. También Poirier lo pone de presente en otro apartado:

No podemos pensar ese imaginario social que crea el lenguaje, que crea las instituciones, que crea la forma misma de la institución -la cual no tiene sentido sin la perspectiva de la psiquis singular- sino como capacidad creadora del colectivo anónimo que surge toda vez que los seres humanos se reúnen y que en cada oportunidad adopta una figura singular, instituida, para existir (Castoriadis citado por Poirier, 2006, p. 62).

Me parece que la observación central aquí es que hay algo nuevo que se genera cuando los sujetos se reúnen, se produce algo que cada uno aislado no podría producir. Es cierto. Como también lo es que eso no se produce sin el concurso de cada uno. Y es cierto también que Marx había hecho alguna observación al respecto al que nombró de modo especial, en inglés, el general intellect.

Pero, lo más elocuente es que Lacan no sólo hizo una fundación del descubrimiento freudiano sobre la observación del carácter estructurante del Otro, del discurso del Otro, que Castoriadis mismo nombra en su texto. El Otro cultural, social, el Gran Otro, escrito con mayúscula, en cuyo seno surge el sujeto. Además, en 1964 funda la Escuela Francesa de Psicoanálisis, institución encargada de la formación psicoanalítica, donde formula una propuesta que permita a cada uno hacer potenciar su creatividad en el colectivo y al mismo tiempo enriquecer al grupo. Esa propuesta es el cartel, donde lo imaginario tiene un papel en la transferencia de trabajo, que sería su preocupación y recibiría nuevos aportes a su formalización en la Escuela de la Causa Freudiana, fundada en 1980, constituida con el cartel como órgano base.

Lo que quiero decir es que preocupa la fácil adopción que se hace de autores optimistas y la descalificación gratuita de autores que cuesta más trabajo conocer. El texto de Ángel Carretero, por ejemplo, pone en boca de Freud palabras que jamás mencionó, pues lo imaginario no es una de sus categorías, además, veamos cómo ubica su praxis (clínica) en nichos filosóficos:

Tanto Marx como Freud, embebidos de un deconstructor racionalismo materialista [?], por otra 
parte perfectamente comprensible[?] desde el contexto intelectual de su época, sospechan de la naturaleza de lo imaginario, catalogándola, de modo simplificador, de falsa conciencia ideológica o de delirio sublimatorio (Carretero, 2003, p. 95).

Al final de este fragmento hay una cita en la que el lector espera (en vano) encontrar palabras de Freud que den fe de la afirmación que acaba de adjudicarle, pero la cita sólo menciona a Gilbert Dürand y Gaston Bachelard (Carretero, 2003, p. 95). Este es un ejemplo del reiterado trato que dan a la obra de Freud comentaristas que sin comprenderla ni citarla, osan difamarla. Ángel Carretero afirma también que Freud habría expresado: "sospechas sobre lo imaginario" y que lo habría definido como "delirio sublimatorio", expresión espuria, puesto que para Freud el delirio es material de análisis como construcción característica de la psicosis, equivalente de los sueños, los olvidos, los chistes, en la neurosis. La sublimación, de otro lado, constituye uno de los destinos más afortunados que pueden tener las pulsiones. Por tanto, la expresión "delirio sublimatorio" es incoherente.

\section{Consideraciones y preguntas finales}

Castoriadis rechaza sancionar la existencia negando el tiempo a favor del cumplimiento de ciertas leyes:

Los "sucesos" no son pues más que la realización de las leyes y la "historia" no es más que el despliegue, a lo largo de una cuarta dimensión, de una "sucesión" que sólo es simple coexisten- cia para un espíritu absoluto (o para la teoría científica acabada) (Castoriadis, 1988, p. 65).

Si bien con su creación ontológica contraría el irresistible ascenso que Hegel dirigió hacia el espíritu absoluto, como una concreción ilustrada de los ideales modernos, sin duda su crítica a la Ilustración tiene antecedentes en Nietzsche, Marx y Freud, quienes no sólo descentraron al sujeto, sino minaron las bases del imperativo moderno de progreso. La Modernidad ideó en Occidente este imperativo de mejoramiento, ideal que señala un norte hacia la prosperidad, la optimización, el esclarecimiento, el confort. Eso consuena con un proyecto de autonomía, que se realizaría "plenamente". Nos preguntamos, pues, si el proyecto de "la sociedad como auto-creación que se despliega como historia" (Castoriadis, 1988, p. 73), ¿no podría retomar rumbos perjudiciales? Si la creación imaginaria es incesante y esencialmente indeterminada, ¿por qué habría para Occidente la posibilidad de "una verdadera política"?

Este ejercicio de lectura cruzada permite develar la veta del psicoanálisis en Castoriadis y sus distanciamientos con él a partir de su optimismo sobre el devenir de las sociedades de Occidente. Habría que ser cautelosos con los comentaristas, puesto que si bien pueden ser de gran ayuda para resolver los interrogantes sobre el sentido de un artículo, cada lectura no puede sino constituirse como el sentido particular que elige un sujeto, por ende también puede incurrir en tergiversaciones. Albert Einstein dijo alguna vez que es más fácil desintegrar un átomo que una mala idea, me parece que esta advertencia resalta la importancia de debatir los temas y ante todo de ir a las fuentes. 


\section{Referencias bibliográficas}

Carretero, Á. (2003). La radicalidad de lo imaginario en Cornelius Castoriadis. Revista Anthropos, 198, 95-105.

Castoriadis, C. (1988). Los dominios del hombre: las encrucijadas del laberinto. Barcelona: Gedisa.

Freud, S. (1982). XXII. Nuevas conferencias de introducción al psicoanálisis, y otras obras (1932-1936). Buenos Aires: Amorrortu.

Isacovich, L. (s/f.) Wo Es war, soll Ich werden. Recuperado de: http://www.fundacionbsas.org.ar $/ \mathrm{main} /$ index.php?option $=\mathrm{com}_{-}$ content\&view $=$ article $\&$ id $=89$ : wo-es-warsoll-ich-werden\&catid $=56$ :articulos

Kojeve, A. (1982). La dialéctica del amo y del esclavo en Hegel. Buenos Aires: La Pléyade.
Lacan, J. (1973). L'inconscient freudien et le nôtre Le Séminaire de Jacques Lacan. Livre XI. Les quatre concepts fondamentaux de la psychanalyse. Texte établi par Jacques-Alain Miller. Paris : Éditions du Seuil.

(1975). La function créatrice de la parole, en Le séminaire de Jacques Lacan: Livre I: Les écrits techniques de Freud. Paris: Éditions du Seuil.

(s/f). Texto no establecido del seminario 6 El deseo y su interpretación, dictado de 1958 a 1959. Recuperado de: http://www.tuanalista. com/Jacques-Lacan/12455/Seminario-6-Eldeseo-y-su-interpretacion-pag.366.htm

Poirier, N. (2006). Castoriadis: el imaginario radical. Buenos Aires: Nueva Visión. 